\title{
Regular Breakfast and Blood Lead Levels among Preschool Children
}

\author{
Jianghong Liư ${ }^{1 *}$, Linda McCauley², Charlene Compher ${ }^{1}$, Chonghuai Yan ${ }^{3}$, Xiaoming Shen $^{3}$, Herbert Needleman ${ }^{4}$ \\ and Jennifer A Pinto-Martin ${ }^{1}$
}

\begin{abstract}
Background: Previous studies have shown that fasting increases lead absorption in the gastrointestinal tract of adults. Regular meals/snacks are recommended as a nutritional intervention for lead poisoning in children, but epidemiological evidence of links between fasting and blood lead levels (B-Pb) is rare. The purpose of this study was to examine the association between eating a regular breakfast and $\mathrm{B}-\mathrm{Pb}$ among children using data from the China Jintan Child Cohort Study.

Methods: Parents completed a questionnaire regarding children's breakfast-eating habit (regular or not), demographics, and food frequency. Whole blood samples were collected from 1,344 children for the measurements of B-Pb and micronutrients (iron, copper, zinc, calcium, and magnesium). B-Pb and other measures were compared between children with and without regular breakfast. Linear regression modeling was used to evaluate the association between regular breakfast and log-transformed B-Pb. The association between regular breakfast and risk of lead poisoning ( $\mathrm{B}-\mathrm{Pb} \geq 10 \mu \mathrm{g} / \mathrm{dL}$ ) was examined using logistic regression modeling.

Results: Median B-Pb among children who ate breakfast regularly and those who did not eat breakfast regularly were $6.1 \mu \mathrm{g} / \mathrm{dL}$ and $7.2 \mu \mathrm{g} / \mathrm{dL}$, respectively. Eating breakfast was also associated with greater zinc blood levels. Adjusting for other relevant factors, the linear regression model revealed that eating breakfast regularly was significantly associated with lower B-Pb (beta $=-0.10$ units of log-transformed B-Pb compared with children who did not eat breakfast regularly, $p=0.02$ ).
\end{abstract}

Conclusion: The present study provides some initial human data supporting the notion that eating a regular breakfast might reduce B-Pb in young children. To our knowledge, this is the first human study exploring the association between breakfast frequency and B-Pb in young children.

Keywords: lead exposure lead poisoning nutrition diet nutrients breakfast

\section{Background}

Lead exposure, even at low levels, has been associated with demonstrable deficits in cognition and intelligence [1-6]. The extent and rate of lead absorption are influenced by physiologic factors including age, fasting state, and calcium and iron status [7,8]. Studies have shown that the absorption of lead in the gastrointestinal tract is more rapid in subjects who are in a fasting state $[7,9,10]$. In adults, the absorption rate of lead ranges from $60-80 \%$ among fasting subjects, about 10 times

\footnotetext{
* Correspondence: jhliu@nursing.upenn.edu

'University of Pennsylvania, School of Nursing, 418 Curie Blvd., Room 426,

Claire M. Fagin Hall, Philadelphia, Pennsylvania 19104-6096, USA

Full list of author information is available at the end of the article
}

higher than when ingested with food [7,9]. Micronutrients are thought to interact with lead in the body and previous epidemiologic studies have shown that dietary micronutrient intakes influence $\mathrm{B}-\mathrm{Pb}[8,11,12]$.

Ingested lead is absorbed at higher rates (about 40$50 \%)$ in infants and children than in adults $[7,13]$. Given the observed impact of fasting on lead absorption in adults, eating frequent and regular meals/snacks is recommended by health authorities for preventing lead poisoning in children [14]. In previous epidemiologic studies, B-Pb in children were positively associated with higher intakes of micronutrients such as calcium $[15,16]$ and iron $[17,18]$ and total calorie $[11,12]$. To our knowledge, however, there have been no prior epidemiology

\section{Biomed Central}


studies evaluating the link between breakfast consumption and $\mathrm{B}-\mathrm{Pb}$ in children. After the phase-out of lead in gasoline in the year 2000, the mean blood lead level of children aged 0-14 years in China was $8.1 \mu \mathrm{g} / \mathrm{dL}$, with $23.9 \%$ of children's having B-Pb greater than $10 \mu \mathrm{g} / \mathrm{dL}$, the level established in 1991 as an indication of concern by the US Centers for Disease Control and Prevention (CDC) and adopted by the Ministry of Health of China in 2006 [19]. In this study, we aim to test whether regular breakfast consumption predicts $\mathrm{B}-\mathrm{Pb}$ or risk of lead poisoning in Chinese preschool. Study subjects are the part of the China Jintan Child Cohort Study [20].

\section{Methods}

\section{Data collection}

Institutional review board approval was obtained from the University of Pennsylvania and the ethical committee for research at Jintan Hospital in Jintan, China. Four pre-schools (Jianshe, Huacheng, Xuebu, and Huashan) were chosen to represent city, suburban, and rural areas, respectively. Between Fall 2004 and Spring 2005, 1,757 male and female children (aged 3 to 5 years) attending the four preschools were invited to participate in this study. Parents of 1,656 (94\%) children signed informed consents to approve their child's participation. A questionnaire containing questions regarding breakfast-eating habit (regular or not), demographics (gender, age, parental educations, parental occupations, and passive smoking exposure), and eating behaviors was completed by a parent. Eating breakfast regularly was defined as eating breakfast at least five days per week. We also conducted three days of 24-hours dietary recall in a subset of study population. The forms were given to the parents of children and collected by the research assistants on the following day. The intake of lunch for two weekdays at school was observed by research assistants (MPH students from South Eastern University). These dietary records were analyzed using the self-developed computerized nutrients assessment system which was similar to Food Processor (Food Processor; ESHA Research, Salem, OR).

Blood specimens of 1,344 children were collected by trained pediatric nurses using a strict research protocol to avoid lead contamination. We were not able to successfully collect blood samples from some children due to a variety of reasons (e.g. parents did not allow blood drawn, blood specimen not viable), but there were no differences in demographics between children with $(\mathrm{n}=$ $1344)$ and without blood samples $(\mathrm{n}=312)$. Samples were frozen and shipped to the Research Center for Environmental Medicine of Children at Shanghai Jiaotong University for the analysis of lead and micronutrients (iron $[\mathrm{Fe}]$, copper $[\mathrm{Cu}]$, zinc $[\mathrm{Zn}]$, calcium $[\mathrm{Ca}]$, and magnesium $[\mathrm{Mg}]$ ) concentrations in blood, using graphite furnace atomic absorption spectrophotometer $[21,22]$. This laboratory has participated successfully in a CDC-administered quality-control program (Blood Lead Proficiency Testing Program) for the measurement of lead in whole blood. Analysis of each specimen was conducted using a replication procedure, and the mean of the repeated measurements was taken as the final measure. Blood lead reference materials for quality control (QC) were provided by Kaulson Laboratories, New Jersey. QC samples were inserted blindly among the study samples (one QC sample in every 10 study samples. Limit of detection (LOD) of B-Pb was $1.8 \mathrm{ug} / \mathrm{dL}$ and half of LOD was imputed for $3(0.2 \%)$ samples under LOD, which was among multiple runs (mean LOD).

\section{Statistical analysis}

Demographic characteristics of children and parents/ grandparents, nutrient and blood lead levels were compared between children eating breakfast regularly and those not eating breakfast regularly (defined as breakfast consumption at least five mornings per week), using chi-square test for categorical variables and t-test or Wilcoxon rank sum test for continuous variables (means or medians). Multivariate stepwise linear regression models of the dependent variable log-transformed $\mathrm{B}-\mathrm{Pb}$ were fitted including breakfast frequency (regular vs. irregular) and other covariates such as demographic characteristics (children's age, gender, parental educations and occupations, grandparental educations), children's nutrient levels in blood, passive smoking, breast feeding history, and breakfast type (rice/noodle, meat mostly, and fruit mostly). A final model was obtained by applying a backwards elimination procedure using variables correlated with $\mathrm{B}-\mathrm{Pb}$ with a $\mathrm{p}$-value $<0.10$. Logistic regression analysis was also performed to examine the associations between breakfast frequency and lead poisoning (B-Pb $\geq 10 \mu \mathrm{g} / \mathrm{dL})$. All analyses were done in SAS 9.2 (SAS Institute, Cary, NC).

\section{Results}

Demographic variables for the entire sample and by regular breakfast eating groups are in Table 1 . Children eating breakfast regularly had a lower median $\mathrm{B}-\mathrm{Pb}(6.1$ vs. 7.2 $\mu \mathrm{g} / \mathrm{dL}$, Wilcoxon test without controlling for covariates, $\mathrm{P}<0.01$ ) compared to those without regular breakfast consumption. Proportions of lead poisoning $(\mathrm{B}-\mathrm{Pb}>=10 \mu \mathrm{g} / \mathrm{dL})$ were $8 \%$ among children with regular breakfast eating habit and $10 \%$ among those not eating breakfast regularly, but this difference is not statistically significant (chi-square test). Sixty-four percent of children eating breakfast regularly and $68 \%$ of children without regular breakfast had moderately high B$\mathrm{Pb}$ (in the range of 5 and $10 \mu \mathrm{g} / \mathrm{dL}$ ). There were no differences in gender and age distributions between 
Table 1 Basic and nutritional factors among children

\begin{tabular}{|c|c|c|c|c|}
\hline \multicolumn{5}{|c|}{ Regular breakfast? } \\
\hline Characteristics & No & Yes & $P$ value $^{\ddagger}$ & Total \\
\hline \multicolumn{5}{|l|}{ Blood lead level ( $\mu \mathrm{g} / \mathrm{dL})$} \\
\hline${\text { Median }(\mathrm{P} 5, \mathrm{P} 95)^{+}}^{+}$ & $7.2(2.9,12.8)$ & $6.1(2.7,10.9)$ & 0.008 & $6.2(2.8,10.9)$ \\
\hline$>=10 \mu \mathrm{g} / \mathrm{dL}, \mathrm{n}(\%)$ & $8(10.4)$ & $92(7.9)$ & 0.43 & $100(8.0)$ \\
\hline Gender & & & 0.63 & \\
\hline Boy & $40(51.9)$ & $639(54.8)$ & & $679(54.6)$ \\
\hline$\overline{\text { Girl }}$ & $37(48.1)$ & $527(45.2)$ & & $564(45.4)$ \\
\hline Age & & & 0.08 & \\
\hline 3 & $23(31.2)$ & $314(26.9)$ & & $337(27.1)$ \\
\hline 4 & $18(23.4)$ & 419 (35.9) & & $438(35.2)$ \\
\hline 5 & $35(45.4)$ & $433(37.2)$ & & $468(37.7)$ \\
\hline School Area & & & 0.03 & \\
\hline Urban & $25(32.5)$ & $478(41.0)$ & & $503(40.4)$ \\
\hline Suburban & $27(35.1)$ & $454(38.9)$ & & $481(38.7)$ \\
\hline Rural & $25(32.5)$ & $234(20.1)$ & & $259(20.8)$ \\
\hline Father's education & & & 0.0002 & \\
\hline Less than high school & $46(59.8)$ & $438(37.6)$ & & $484(38.9)$ \\
\hline High school & $21(27.3)$ & $378(32.4)$ & & $399(32.1)$ \\
\hline College \& University & $10(13.0)$ & $350(30.0)$ & & $360(29.0)$ \\
\hline Mother's education & & & 0.0003 & \\
\hline Less than high school & $56(72.3)$ & $575(49.3)$ & & $631(50.8)$ \\
\hline High school & $15(19.5)$ & $351(30.1)$ & & $366(29.4)$ \\
\hline College \& University & $6(7.8)$ & $240(20.6)$ & & $246(19.8)$ \\
\hline Father's occupation & & & 0.005 & \\
\hline Unemployed & $3(3.9)$ & $46(3.9)$ & & $49(3.9)$ \\
\hline General labor & $50(64.9)$ & $595(51.0)$ & & $645(51.9)$ \\
\hline Technician/Professional & $15(19.5)$ & $450(38.6)$ & & $465(37.5)$ \\
\hline Other & $9(11.7)$ & $75(6.4)$ & & $84(6.8)$ \\
\hline Mother's occupation & & & 0.04 & \\
\hline Unemployed & $3(3.9)$ & $67(5.8)$ & & $70(5.6)$ \\
\hline General labor & $37(48.1)$ & $475(40.7)$ & & $512(41.2)$ \\
\hline Technician/Professional & $12(15.6)$ & $344(29.5)$ & & $356(28.6)$ \\
\hline Other & $25(32.5)$ & $280(24.0)$ & & $305(24.5)$ \\
\hline Parents divorces or separated & & & 0.89 & \\
\hline Yes & $3(4.6)$ & $46(4.3)$ & & $49(4.3)$ \\
\hline No & $62(95.4)$ & $1030(95.7)$ & & $1092(95.7)$ \\
\hline Grandfather's education & & & 0.007 & \\
\hline None & $17(22.1)$ & $139(11.9)$ & & $156(12.6)$ \\
\hline$<=9$ years & $29(37.7)$ & $591(50.7)$ & & $620(49.9)$ \\
\hline$>9$ years & $31(40.3)$ & $436(37.4)$ & & $467(37.5)$ \\
\hline Grandmother's education & & & 0.01 & \\
\hline None & $22(28.6)$ & $209(17.9)$ & & $231(18.6)$ \\
\hline$<=9$ years & $19(24.7)$ & $483(41.4)$ & & $502(40.3)$ \\
\hline$>9$ years & $36(46.7)$ & $474(40.7)$ & & $512(41.1)$ \\
\hline Passive smoking & & & 0.34 & \\
\hline Yes & $46(59.8)$ & $632(54.2)$ & & $678(54.5)$ \\
\hline$\overline{\text { No }}$ & $31(40.2)$ & $534(45.8)$ & & $565(45.5)$ \\
\hline
\end{tabular}


Table 1 Basic and nutritional factors among children (Continued)

\begin{tabular}{|c|c|c|c|c|}
\hline \multicolumn{2}{|c|}{ Feeding method (during the first year) } & \multicolumn{3}{|c|}{0.42} \\
\hline Breast feeding & $63(82.9)$ & $889(76.5)$ & & $952(76.9)$ \\
\hline Bottle (formula) feeding & $5(6.6)$ & $92(7.9)$ & & $97(7.8)$ \\
\hline Mixed & $8(10.5)$ & $181(15.6)$ & & $189(16.3)$ \\
\hline Breakfast type & & & 0.12 & \\
\hline Noodle/Rice & $50(78.1)$ & $760(69.1)$ & & $810(69.9)$ \\
\hline Mixed & $14(21.9)$ & $340(30.9)$ & & $354(30.1)$ \\
\hline \multicolumn{5}{|l|}{ Calcium } \\
\hline Mean \pm SD & $1.66 \pm 0.21$ & $1.64 \pm 0.19$ & 0.45 & $1.64 \pm 0.24$ \\
\hline Number of deficiency (\%) & $31(40.3)$ & $452(38.8)$ & 0.79 & $483(38.9)$ \\
\hline \multicolumn{5}{|l|}{$\mathrm{Cu}$} \\
\hline Mean \pm SD & $26.96 \pm 7.10$ & $27.03 \pm 6.80$ & 0.83 & $27.05 \pm 6.64$ \\
\hline Number of deficiency (\%) & $1(1.3)$ & $6(0.5)$ & 0.34 & $7(0.6)$ \\
\hline \multicolumn{5}{|l|}{ Fe } \\
\hline Mean \pm SD & $8.12 \pm 0.87$ & $8.13 \pm 0.84$ & 0.68 & $8.13 \pm 0.83$ \\
\hline Number of deficiency (\%) & $21(27.3)$ & $280(24.0)$ & 0.51 & $301(24.2)$ \\
\hline \multicolumn{5}{|l|}{$\mathrm{Mg}$} \\
\hline Mean \pm SD & $1.50 \pm 0.17$ & $1.47 \pm 0.16$ & 0.10 & $1.47 \pm 0.16$ \\
\hline Number of deficiency (\%) & 0 & $4(0.3)$ & 0.61 & $4(0.3)$ \\
\hline \multicolumn{5}{|l|}{$Z n^{* *,+}$} \\
\hline Mean \pm SD & $78.25 \pm 12.51$ & $82.70 \pm 13.27$ & 0.008 & $82.46 \pm 13.40$ \\
\hline Number of deficiency (\%) & $41(53.2)$ & $436(37.4)$ & 0.006 & $477(38.3)$ \\
\hline
\end{tabular}

${ }^{\ddagger}, \mathrm{P}$ value, comparison between children with and without regular breakfast; ${ }^{+}, \mathrm{P}<0.01$, Wilcoxon test (covariates were not adjusted).

children eating breakfast regularly and those not. Six percent (40/679) of boys and seven percent (47/564) of girls did not eat breakfast regularly. Children eating breakfast regularly tended to live in urban (41\%) and suburban (39\%) areas. Grandparent and parent characteristics were correlated with breakfast frequency. Grandparents of children who eat breakfast regularly were more likely to be educated. Parents of children who eat breakfast regularly were more likely to have higher education (30\% of fathers and $20 \%$ of mothers finished college) and to be technicians and professional workers (39\% of fathers and $30 \%$ mothers), as compared to those who did not regularly eat breakfast ( $13 \%$ of fathers and $8 \%$ of mothers finished college). There were no statistical differences in micronutrient levels other than higher Zinc ( $\mathrm{Zn}$ ) levels among children who ate breakfast regularly.

Our final linear regression model showed that higher breakfast frequency was associated with lower $\mathrm{B}-\mathrm{Pb}$ (beta $=-0.10$ units of log-transformed $\mathrm{B}-\mathrm{Pb}$ compared with children who did not eat breakfast regularly, $\mathrm{p}=$ 0.02) after controlling for covariates (Table 2). This beta, when calculate back to original scale of $\mathrm{B}-\mathrm{Pb}$, means that children eating breakfast regularly had 0.8 $\mu \mathrm{g} / \mathrm{dL}$ (or $10 \%$ ) lower $\mathrm{B}-\mathrm{Pb}$ than those did not eat breakfast regularly after excluding the impacts of other factors. Other covariates including gender, age, living area, mother's education, and father's occupation were also predictors of $\mathrm{B}-\mathrm{Pb}$. While being a boy, living in a rural area, older age, and parents as professional workers were associated with higher $\mathrm{B}-\mathrm{Pb}$, children of mothers with higher education tended to have lower B$\mathrm{Pb}$. In a linear regression model of 270 children with data of calculated daily dietary intake of micronutrients ( $\mathrm{Ca}, \mathrm{Fe}, \mathrm{Zn}, \mathrm{Cu}, \mathrm{Mg}$, and vitamins), we did not find associations between dietary intakes of minerals and log-transformed $\mathrm{B}-\mathrm{Pb}$ (data not shown). In the Logistic regression model of lead poisoning risk (Table 3), boys had 1.92 higher odds of being lead poisoning than girls, and that father's university level education reduced the odds to 0.38 times that of father with less than high school education. Compared with 3-year-old children, 4year or 5-year old children had about 2 time odds of being lead poisoning. Regular breakfast, however, did not predict lead poisoning $(\mathrm{B}-\mathrm{Pb} \geq 10 \mu \mathrm{g} / \mathrm{dL})$. Blood micronutrient levels were not associated with $\mathrm{B}-\mathrm{Pb}$ or the risk of lead toxicity (data not shown).

\section{Discussion}

Previous studies showed that an empty stomach increases the absorption of lead and thus elevates $\mathrm{B}-\mathrm{Pb}$ in adults, but it not clear if this effect exists in children 
Table 2 Final multiple linear regression of log transformed $\mathrm{B}-\mathrm{Pb}$ among children $(\mathrm{R}$ square $\mathbf{0} \mathbf{0 . 1 4})$

\begin{tabular}{|c|c|c|c|}
\hline Variable & $\begin{array}{c}\text { Parameter } \\
\text { (beta)Estimate }\end{array}$ & StandardError & $\begin{array}{c}\mathrm{P} \\
\text { value } \\
\end{array}$ \\
\hline Regular breakfast & -0.10 & 0.04 & 0.02 \\
\hline Sex (reference: boy) & -0.11 & 0.02 & $<.0001$ \\
\hline \multicolumn{4}{|l|}{ Age (reference: 3 years) } \\
\hline 4 & 0.19 & 0.03 & $<.0001$ \\
\hline 5 & 0.31 & 0.03 & $<.0001$ \\
\hline \multicolumn{4}{|c|}{$\begin{array}{l}\text { School area (reference: urban } \\
\text { area) }\end{array}$} \\
\hline Suburban & 0.02 & 0.02 & 0.45 \\
\hline Rural & 0.07 & 0.03 & 0.02 \\
\hline \multicolumn{4}{|l|}{$\begin{array}{l}\text { Mother's education } \\
\text { (reference: less than high } \\
\text { school) }\end{array}$} \\
\hline High school & -0.07 & 0.03 & 0.01 \\
\hline College \& University & -0.01 & 0.04 & 0.77 \\
\hline \multicolumn{4}{|l|}{$\begin{array}{l}\text { Father's occupation } \\
\text { (reference: unemployed) }\end{array}$} \\
\hline General labor & 0.08 & 0.06 & 0.15 \\
\hline Technician/Professional & 0.13 & 0.06 & 0.04 \\
\hline Other & 0.04 & 0.07 & 0.55 \\
\hline \multicolumn{4}{|l|}{$\begin{array}{l}\text { Mother's occupation } \\
\text { (reference: unemployed) }\end{array}$} \\
\hline General labor & -0.05 & 0.05 & 0.36 \\
\hline Technician/Professional & -0.10 & 0.06 & 0.07 \\
\hline Other & -0.06 & 0.05 & 0.28 \\
\hline
\end{tabular}

as well. There have been no other studies directly quantifying the impact of regular breakfast consumption on lead absorption in children. In this analysis, we found that median $\mathrm{B}-\mathrm{Pb}$ in those children who eat breakfast regularly was about $15 \%$ lower than that in children who do not eat breakfast regularly. This study provides important early evidence supporting the hypothesis that eating regular meals such as breakfast is associated with lower $\mathrm{B}-\mathrm{Pb}$ in children. To our knowledge, this is the first human study exploring the association between breakfast frequency and B-Pb in young children. Eating frequent and regular meals (including breakfast) and snacks have been recommended by many health organizations for preventing and reducing lead poisoning in children, and these data concur. For example, the U.S. Advisory Committee on Childhood Lead Poisoning Prevention recommends that caregivers provide regular meals and snacks to young children [14].

A number of studies have shown that food in the gastrointestinal tract reduces the absorption of ingested lead in adults $[7,9,10,23]$. Experimental studies showed that the bioavailability of ingested lead in adults when taken with a meal was about 10 times lower than that when ingested after fasting [7]. The smaller magnitude
Table 3 Multiple Logistic regression analysis of elevated B-Pb

\begin{tabular}{|c|c|c|c|}
\hline Variable & ORs & $95 \% \mathrm{Cl}$ & $P$ value \\
\hline \multicolumn{4}{|l|}{ Regular breakfast } \\
\hline No & Reference & & \\
\hline Yes & 0.82 & $0.37 \sim 1.79$ & 0.61 \\
\hline \multicolumn{4}{|l|}{ Sex } \\
\hline Girl & Reference & & \\
\hline Boy & 1.92 & $1.23 \sim 3.01$ & 0.004 \\
\hline \multicolumn{4}{|l|}{ Age (Years) } \\
\hline 3 & Reference & & \\
\hline 4 & 1.97 & $1.03 \sim 3.77$ & 0.27 \\
\hline 5 & 2.33 & $1.24 \sim 4.38$ & 0.03 \\
\hline \multicolumn{4}{|l|}{ School area } \\
\hline Urban & Reference & & \\
\hline Suburban & 0.72 & $0.40 \sim 1.20$ & 0.15 \\
\hline Rural & 1.05 & $0.62 \sim 1.78$ & 0.39 \\
\hline \multicolumn{4}{|l|}{ Father's education } \\
\hline Less than high school & Reference & & \\
\hline High school & 0.97 & $0.58 \sim 1.58$ & 0.07 \\
\hline College \& university & 0.38 & $0.17 \sim 0.84$ & 0.01 \\
\hline \multicolumn{4}{|l|}{ Mother's education } \\
\hline Less than high school & Reference & & \\
\hline High school & 0.85 & $0.50 \sim 1.45$ & 0.92 \\
\hline College \& university & 0.76 & $0.31 \sim 1.91$ & 0.66 \\
\hline \multicolumn{4}{|l|}{ Father's occupation } \\
\hline Unemployed & Reference & & \\
\hline General labor & 1.20 & $0.34 \sim 4.28$ & 0.35 \\
\hline Technician/professional & 2.28 & $0.61 \sim 8.55$ & 0.09 \\
\hline Other & 1.75 & $0.42 \sim 7.31$ & 0.61 \\
\hline \multicolumn{4}{|l|}{ Mother's occupation } \\
\hline Unemployed & Reference & & \\
\hline General labor & 1.65 & $0.54 \sim 5.04$ & 0.21 \\
\hline Technician/professional & 1.29 & $0.38 \sim 4.42$ & 0.94 \\
\hline Other & 1.22 & $0.38 \sim 3.85$ & 0.85 \\
\hline
\end{tabular}

ORs: odds ratios; $95 \% \mathrm{Cl}$ : 95\% confidence interval.

of the influence in children ( $15 \%$ change) may due to relatively lower lead exposure dose in children, observational study design, and the difference in the kinetics of lead between children and adults.

The mechanisms behind the impact of fasting on gastrointestinal tract absorption of lead are not well understood. Mineral micronutrients, especially the presence of calcium and phosphate in the intestinal lumen, may play a role by competing with lead for absorption [7]. Epidemiologic studies have shown increasing dietary calcium intake is inversely associated with $\mathrm{B}-\mathrm{Pb}$ in children $[15,16]$. Higher dietary iron intake is also associated with lower $\mathrm{B}-\mathrm{Pb}$ in the U.S. children $[17,18]$. In the 
present study, however, we did not find significant associations between blood levels of these mineral micronutrients and $\mathrm{B}-\mathrm{Pb}$. We did find significantly higher blood levels of zinc in children who ate breakfast regularly, which may suggest that their dietary zinc intake was greater and perhaps competed with lead for absorption. Our analysis of dietary micronutrient intake in a subgroup of 270 children, however, did not suggest higher zinc intake in regular breakfast eaters. In previous studies, while some studies observed associations between dietary intake/supplementation $(\mathrm{Ca}, \mathrm{Fe}$, and $\mathrm{Zn})$ and $\mathrm{B}$ $\mathrm{Pb}[8,15-17]$ others did not $[11,24]$. In a study in the US, Gallicchio et al. did not found associations between B$\mathrm{Pb}$ and daily micronutrient intakes (iron, calcium, vitamin $C$, or vitamin D) after controlling lead exposure and child's age [11]. A clinical trial showed that Ca supplementation did not statistically significantly change B$\mathrm{Pb}$ among children 1 to 6 years of age when $\mathrm{B}-\mathrm{Pb}$ were 10- $45 \mu \mathrm{g} / \mathrm{dL}$ [24]. There are two possible explanations for the inconsistency with this study. First, B-Pb are lower than those in previous studies. Second, children in this study are younger than the ones in previous studies.

The associations between socio-demographic factors and $\mathrm{B}-\mathrm{Pb}$ found in previous studies were also observed in the present study [19,25-29]. Some of these factors including age and gender are strongly associated with B$\mathrm{Pb}$, but not modifiable. Other factors including living area and parental education and occupation might not be possible to improve solely through public health intervention. Targeting children's breakfast consumption habits is relatively more feasible at both the family and community levels.

Several limitations must be considered when interpreting the findings from the present study. We have no data on the key variable of environmental lead exposure, a factor that might explain the higher $\mathrm{B}-\mathrm{Pb}$ and greater risk of toxicity in older children if cumulative lead exposure increases over time. Clearly, our findings regarding increased $\mathrm{B}-\mathrm{Pb}$ with increasing age merit repeated measures over time together with measures of environmental lead. We have information of dietary intake of micronutrients on only 270 of the larger sample of 1344 children, and thus cannot be certain that these micronutrient intake levels are representative of the entire group. Parental report of regular breakfast consumption in their children may lead to bias and misclassification. A guide was provided to parents to answer this question. However, for those children primarily living with their grandparents, the information may be less accurate. We did not ask parents the number of days the child ate breakfast during the week but instead used an arbitrary definition of "at least 5 days per week" as an indication of regular breakfast consumption. This was suggested by our local partners who believed that this would reasonably distinguish children. Second, the association observed in this cross-sectional study may not represent a causal relationship. There may be a tendency for higher B-Pb's to be associated with a decreased appetite for eating breakfast. Given the data collected from this study, we cannot determine to what extent appetite affected the reported breakfast consumption. Third, the lack of association in the multivariate logistic regression analysis on lead poisoning is likely due to the limited magnitude of nutritional influence at relative low exposure level [24] and the small number of children with elevated B-Pb $(7.9 \%$ for children with regular breakfast and $10.4 \%$ for children with irregular breakfast). Fourth, other potential confounders (e.g., household income and drinking water source) which were not assessed or included in the multiple regression models might contribute to the lower $\mathrm{B}-\mathrm{Pb}$ observed among children who ate breakfast regularly. Finally, given the impact of fasting on lead absorption, regular breakfast is expected to modify the associations between external exposure levels and $\mathrm{B}-\mathrm{Pb}$ which we cannot examine in this study due to lack of external exposure data.

Our findings, if replicated in future studies, have three practical implications. First, the importance of breakfast consumption as a strategy to increase meal frequency is suggested. Second, our data suggest that the risk of lead toxicity and higher $\mathrm{B}-\mathrm{Pb}$ increases over time, a finding that suggests consideration of environmental routes of lead exposure. Third, we found that parental characteristics are major determinants of children's breakfast frequency. Children from families with higher parental education levels and technicians/professional workers are more likely to have regular breakfast. This indicates that parents play important role in increasing children's breakfast frequency which may in turn reduce $\mathrm{B}-\mathrm{Pb}$. Promotion of parents' and child care givers' awareness of the importance of breakfast as a proactive protective factor in reducing childhood $\mathrm{B}-\mathrm{Pb}$ should become a part of all lead prevention programs. Because both lead exposure [1-6,30-33] and malnutrition [34-37]are related to children's negative cognitive and behavioral outcomes, promotion of regular breakfast in children can potentially enhance both physical and mental health wellbeing.

\section{Conclusions}

This study provided epidemiological evidence that increasing breakfast frequency could reduce $\mathrm{B}-\mathrm{Pb}$ in young children. Parental or caregivers' characteristics including education and occupation are major determinants of breakfast frequency, indicating that improving their knowledge about nutrition and $\mathrm{B}-\mathrm{Pb}$ might help to prevent lead poisoning. 


\section{List of Abbreviation}

B-Pb: blood lead Levels; CDC: Centers for Disease Control and Prevention; QC: Quality Control; Fe: iron; Cu: copper; Zn: zinc; Ca: calcium; Mg: magnesium

\section{Acknowledgements}

National Institute of Environment Health Sciences (NIEHS, K01-ES015 877; R01-ES018858) US; UPenn CEET P30 ES013508; The Wacker Foundation US; Jintan City Government; Jintan Hospital, China. Thanks are extended to the participating children and their families from Jintan City, and to the Jintan Cohort Study Group. We are very grateful to the Jintan city government and the Jintan Hospital for their support and assistance.

\section{Author details}

'University of Pennsylvania, School of Nursing, 418 Curie Blvd., Room 426, Claire M. Fagin Hall, Philadelphia, Pennsylvania 19104-6096, USA. ${ }^{2}$ Emory University, Nell Hodgson School of Nursing, 1520 Clifton Rd NE \# 402, Atlanta, GA 30322-4201, USA. ${ }^{3}$ Shanghai Jiaotong University School of Medicine, 1665 Kong Jiang Road, Shanghai 200092, China. ${ }^{4}$ University of Pittsburgh, UPMC, 200 Lothrop St., Pittsburgh, PA 15213-2582, USA.

\section{Authors' contributions}

$J$ conducted data collection, data analysis, data interpretation, and manuscript preparation. LM, CC, and JP conducted data interpretation and manuscript preparation. CY and XS conducted blood lead analysis. All authors read and approved the final manuscript.

\section{Competing interests}

The authors declare that they have no competing interests.

Received: 28 October 2010 Accepted: 1 April 2011

Published: 1 April 2011

\section{References}

1. Bellinger DC: Very low lead exposures and children's neurodevelopment. Current Opinion in Pediatrics 2008, 20:172-177.

2. Lanphear BP, Hornung Khoury RJ, Yolton K, Baghurst P, Bellinger DC, Canfield RL, Dietrich KN, Bornschein R, Greene T, Rothenberg SJ, Needleman HL, Schnaas L, Wasserman G, Graziano J, Roberts R: Low-Level Environmental Lead Exposure and Children's Intellectual Function: An International Pooled Analysis. Environ Health Perspect 2005, 113(7):894-899.

3. Needleman HL: Low level lead exposure and the development of children. Southeast Asian J Trop Med Public Health 2004, 35:252-254.

4. Shen XM, Wu SH, Yan CH: Impacts of low-level lead exposure on development of children: Recent studies in China. Clinica Chimica Acta 2001, 313:217-220

5. Weiss B, Cory-Slechta D, Gilbert SG, Mergler D, Miller E, Miller C, Newland MC, Rice D, Schettler T: The new tapestry of risk assessment. NeuroToxicology 2008, 29:883-890.

6. Dietrich KN, Krafft KM, Bornschein RL, Hammond PB, Berger O, Succop PA, Bier M: Low-Level Fetal Lead Exposure Effect on Neurobehavioral Development in Early Infancy. Pediatrics 1987, 80:721-730.

7. Agency for Toxic Substances and Disease Registry: Toxicological profile for lead. Book Toxicological profile for lead City: US Department of Health and Human Services, Public Health Service, Agency for Toxic Substances and Disease Registry; 2007 [http://www.atsdr.cdc.gov/toxprofiles/tp13.pdf].

8. Ahamed M, Siddiqui MKJ: Environmental lead toxicity and nutritional factors. Clinical Nutrition 2007, 26:400-408.

9. James HM, Hilburn ME, Blair JA: Effects of Meals and Meal Times on Uptake of Lead from the Gastrointestinal Tract in Humans. Human Toxicol 1985, 4:401-407.

10. Rabinowitz RB, Kopple JD, Wetherill GW: Effect of food intake and fasting on gastrointestinal lead absorption in humans. Am J Clin Nutrit 1980, 33:1784-1788.

11. Gallicchio L, Scherer RW, Sexton M: Influence of nutrient intake on blood lead levels of young children at risk for lead poisoning. Environmental Health Perspectives 2002, 110:A767-A772.

12. Lucas SR, Sexton M, Langenberg P: Relationship between blood lead and nutritional factors in preschool children: A cross-sectional study. Pediatrics 1996, 97:74-78.
13. Lidsky TI, Schneider JS: Lead neurotoxicity in children: basic mechanisms and clinical correlates. Brain 2003, 126:5-19.

14. Managing Elevated Blood Lead Levels Among Young Children: Recommendations from the Advisory Committee on Childhood Lead Poisoning Prevention. [http://www.cdc.gov/nceh/lead/casemanagement/ casemanage_chap6.htm]

15. Lacasana M, Romieu I, Sanin LH, Palazuelos E, Hernandez-Avila M: Blood lead levels and calcium intake in Mexico City children under five years of age. International Journal of Environmental Health Research 2000, 10:331-340.

16. Mahaffey KR, Gartside PS, Glueck CJ: Blood lead levels and dietary calcium intake in 1- to 11-year-old children: The Second National Health and Nutrition Examination Survey, 1976 to 1980. Pediatrics 1986, 78:257-262.

17. Hammad TA, Sexton M, Langenberg P: Relationship between blood lead and dietary iron intake in preschool children: A cross-sectional study. Annals of Epidemiology 1996, 6:30-33.

18. Zimmermann MB, Muthayya S, Moretti D, Kurpad A, Hurrell RF: Iron fortification reduces blood lead levels in children in Bangalore, India. Pediatrics 2006, 117:2014-2021.

19. He K, Wang S, Zhang J: Blood lead levels of children and its trend in China. Science of the Total Environment 2009, 407:3986-3993.

20. Liu J, McCauley LA, Zhao Y, Zhang H, Pinto-Martin J: Cohort profile: The China Jintan Child Cohort Study. Int/ J Epidemiol 2010, 39:668-674.

21. Shen $\mathrm{X}$, Zhou J, Yan C: The methodology of BPb level measurement by flamele GF-AAS. J Trace Element Res 1994, 11:43-48.

22. Yan C, Shen X, Zhang Y: An epidemiological survey on blood lead level and high risk factors for lead poisoning of children in Shanghai. Chinese Journal of Pediatrics 1998, 36:142-144.

23. Diamond GL, Goodrum PE, Felter SP, Ruoff WL: Gastrointestinal absorption of metals. Drug Chem Toxicol 1997, 20:345-368.

24. Markowitz ME, Sinnett M, Rosen JF: A Randomized Trial of Calcium Supplementation for Childhood Lead Poisoning. Pediatrics 2004, 113 e34-e39.

25. Jain NB, Hu H: Childhood Correlates of Blood Lead Levels in Mumbai and Delhi. Environ Health Perspect 2006, 114:466-470.

26. Levin R, Brown MJ, Kashtock ME, Jacobs DE, Whelan EA, Rodman J, Schock MR, Padilla A, Sinks T: Lead exposures in U.S. children, 2008: Implications for prevention. Environmental Health Perspectives 2008, 116:1285-1293

27. Moralez LS, Gutierrez P, Escarce JJ: Demographic and socioeconomic factors associated with blood lead levels among Mexican-American children and adolescents in the United States. Public Health Reports 2005, 120:448-454.

28. Roy A, Hu H, Bellinger DC, Palaniapan K, Wright RO, Schwartz J, Balakrishnan K: Predictors of blood lead in children in Chennai, India (2005-2006). International Journal of Occupational and Environmental Health 2009, 15:351-359.

29. Zhang SM, Dai YH, Xie XH, Fan ZY, Tan ZW, Zhang YF: Surveillance of childhood blood lead levels in 14 cities of China in 2004-2006. Biomedical and Environmental Sciences 2009, 22:288-296.

30. Hubbs-Tait L, Nation J, Krebs N, Bellinger D: Neurotoxicants, Micronutrients, and Social Environments. Individual and Combined Effects on Children's Development. Psychological Science in the Public Interest 2005, 6:57-121.

31. Chen A, Cai B, Dietrich KN, Radcliffe J, Rogan WJ: Lead exposure, IQ, and behavior in urban 5 - to 7-year-olds: does lead affect behavior only by lowering IQ? Pediatrics 2007, 119(3):e650-8.

32. Liu J: Early health risk factors for violence: Conceptualization, review of the evidence, and implications. Aggression and Violent Behavior 2011, 16:63-73.

33. Rademacher DJ, Steinpreis RE, Weber DN: Effects of dietary lead and/or dimercaptosuccinic acid exposure on regional serotonin and serotonin metabolite content in rainbow trout (Oncorhynchus mykiss). Neurosci Lett 2003, 339:156-160

34. Liu J, Raine A, Venables P, Dalais C, Mednick SA: Malnutrition at age 3 years and lower cognitive ability at age 11 years: independence from psychosocial adversity. Archives of Pediatrics \& Adolescent Medicine 2003, 157:593-600.

35. Galler JR, Waber D, Harrison R, Ramsey F: Behavioral effects of childhood malnutrition. American Journal of Psychiatry 2005, 162:1760-1. 
36. Liu J, Raine A, Venables P, Mednick SA: Malnutrition at age 3 years and externalizing behavior problems at ages 8,11 , and 17 years. American Journal of Psychiatry 2004, 161:2005-2013.

37. Liu J, Raine A: The effect of childhood malnutrition on externalizing behavior. Current Opinion in Pediatrics 2006, 18:565-570.

doi:10.1186/1476-069X-10-28

Cite this article as: Liu et al: Regular Breakfast and Blood Lead Levels among Preschool Children. Environmental Health 2011 10:28.

Submit your next manuscript to BioMed Central and take full advantage of:

- Convenient online submission

- Thorough peer review

- No space constraints or color figure charges

- Immediate publication on acceptance

- Inclusion in PubMed, CAS, Scopus and Google Scholar

- Research which is freely available for redistribution

Submit your manuscript at www.biomedcentral.com/submit 